\title{
Processos formativos de professoras iniciantes na Educação Infantil
}

\author{
Valéria Menassa Zucolotto* \\ Valdete Côco**
}

\begin{abstract}
Resumo
No reconhecimento da especificidade da primeira etapa da Educação Básica e na compreensão da importância do início da carreira, este artigo, associado à pesquisa "Primeiros anos da carreira docente: diálogos com professoras iniciantes na Educação Infantil", tematiza os aprendizados da docência na relação com a formação inicial e continuada. Com princípios teórico-metodológicos bakhtinianos (BAKHTIN, 2003), em diálogo com o conceito de saberes docentes (TARDIF, 2012), a pesquisa se desenvolveu por meio de uma abordagem qualitativa do tipo exploratória, com procedimentos de entrevista com um grupo de seis professoras. Com os dados, exploramos a necessidade de acompanhamento e apoio institucional às professoras principiantes, as iniciativas em busca de processos formativos e as possibilidades de parcerias com os docentes mais experientes.

Palavras-chave: educação infantil; trabalho docente; início de carreira.
\end{abstract}

\section{Formative Processes of Beginning Teachers in Early Childhood Education}

\begin{abstract}
In recognition of the specificity of the first stage of basic education and understanding of the importance of early career, this article, along with the research "First-Year Teaching Career: Dialogues With Beginning Teachers in Early Childhood Education", thematize the teacher's learning in relation with the initial and continuing education and training. With theoretical and methodological bakhtinian principles (BAKHTIN, 2003), in dialogue with the concept of teacher`s knowledge (TARDIF, 2012), the research was developed through an exploratory qualitative approach, with interview procedures in a group of six teachers. With the data, we explored the need for monitoring and institutional support to beginning teachers, the initiatives searching for training processes and the possibilities of partnerships with more experienced teachers.
\end{abstract}

Keywords: early childhood education; teaching profession; early career.

\section{Introdução}

A concretização do direito à educação, associado à expansão do ensino, vem trazendo à pauta de debates no cenário brasileiro o papel das instituições e da formação de professores envolvidos diretamente nos processos educativos vivenciados pelos indivíduos desde os seus primeiros anos de vida. Nesse contexto, a Educação Infantil (EI) vem sofrendo mudanças estruturais, culminando na sua inserção nos sistemas de ensino, como primeira etapa da Educação Básica, organizada em creches e pré-escolas. Diante disso, o atendimento às crianças de zero a seis anos de idade passa a demandar a profissionalização dos trabalhadores docentes, no bojo de normativas para o trabalho pedagógico que reafirmam a integração entre as ações de cuidado e educação (KRAMER, 2003, CAMPOS, 2007; FERREIRA; CÔCO, 2011). Essa etapa se estrutura com base no cuidar e educar como "um único e indissociável ato promotor" do desenvolvimento integral das crianças, "de forma global e harmônica, nos aspectos físico, social, afetivo e cognitivo" (NUNES; CORSINO; DIDONET, 2011, p. 9).

Nesse sentido, com os avanços no desenvolvimento de políticas públicas para a EI, associadas aos requisitos de profissionalização docente - garantida na Lei de Diretrizes e Bases para a Educação Nacional (BRASIL, 1996), que prevê que os professores de EI tenham formação em nível superior, embora admita-se, ainda, a formação em nível médio - o exercício da docência nessa etapa passa a se desenvolver reconhecendo as especificidades da educação de crianças pequenas, organizando-se por meio de parâmetros próprios (BRASIL, 2006; 2009), a fim de que não se apoie em modelos de docência vinculados ao Ensino Fundamental.

Assim, o contexto institucional da EI, integrando os sistemas de ensino, induz ao reconhecimento da necessidade de uma formação profissional pautada nas funções sociais $\mathrm{e}$ educacionais das instituições (PINAZZA, 2010). Logo, a constituição da carreira docente para essa etapa requer, além de normativas para a formação

* Endereço eletrônico: valeriazucolotto@gmail.com

** Endereço eletrônico: valdetecoco@hotmail.com 
inicial, investimentos em formação continuada. As especificidades da docência na EI se integram a um contexto de discussões e estudos que problematizam a formação (inicial e continuada) e o trabalho docente na Educação Básica em várias dimensões. Há o fortalecimento da ideia de que a formação do professor não termina quando se conclui o curso de graduação, assim como da concepção de formação continuada como um processo contínuo (PEREIRA, 2010). Fortalece-se, especialmente, uma compreensão da necessidade de que os professores tenham a oportunidade de, na própria instituição, apropriar-se e desenvolver conhecimentos e saberes sobre a docência, necessários ao exercício profissional (PLACCO, 2010). Nessa correlação, a falta de apoio ao processo contínuo de formação dos profissionais elimina a potencialidade das instituições educacionais como lócus privilegiado de desenvolvimento profissional (PEREIRA, 2010).

Associamos a estas reflexões a observação de que a formação é um processo que se desenvolve ao longo da vida (NÓVOA, 2007). As questões atinentes ao trabalho docente se descortinam com o avançar da trajetória formativa, em movimentos que unem a formação pessoal e os contextos específicos de atuação profissional. Os docentes são sujeitos capazes de criar e recriar seu desenvolvimento na profissão, formando-se e transformando-se. Na estrutura das transformações pelas quais passam os docentes, Castro (2010) indica que os professores vivenciam ciclos profissionais, que são definidos nas diferentes fases do exercício de sua profissão, desde o início da trajetória profissional - a entrada no mercado de trabalho - até a aposentadoria. A responsabilidade e a autonomia vão crescendo e se reconfiguram à medida que avança o tempo de carreira. Assim, pesquisas sobre vidas de professoras indicam que o início da carreira figura como período importante para a carreira docente (HUBERMAN, 2007; NÓVOA, 2007). Nessa lógica, tomamos como base a perspectiva de que o início da carreira acontece entre um e três anos de trajetória profissional (HUBERMAN, 2007).

Os docentes iniciantes vivenciam situações de intenso aprendizado - de como se relacionar com os educandos, como ensinar, como mediar conflitos -, sendo comum que se deparem com desafios também no que se refere às condições de trabalho e emprego (TARDIF, 2012). Os processos formativos que se desenvolvem nesse momento da carreira dialogam com a configuração dos modos de os professores serem e estarem na profissão, implicados com os comprometimentos do trabalho.
Os debates sobre a vida profissional e os processos formativos têm se constituído essenciais para a análise das políticas públicas de incentivo à escolha e permanência na profissão docente, das demandas para melhoria do desenvolvimento do trabalho e das condições nas quais formação e trabalho se desenvolvem (MARCELO GARCÍA, 1999; NÓVOA, 2007; TARDIF, 2012).

O contexto nacional de carência de estudos sobre professores iniciantes na EI (ZUCOLOTTO; CÔCO, 2012; ZUCOLOTTO, 2012) possibilitou refletir sobre as demandas próprias do trabalho docente nessa etapa da educação básica, em articulação com os desafios da iniciação à docência.

Com esse propósito, realizamos uma pesquisa de mestrado intitulada "Primeiros anos da carreira docente: diálogos com professoras iniciantes na educação infantil", com o objetivo de compreender como se constitui o início da carreira na EI. O estudo, de abordagem qualitativa do tipo exploratória, foi realizado com seis professoras que estavam no segundo ano atuação profissional na EI, por meio de entrevistas semiestruturadas individuais e coletivas. Partindo da hipótese de que o início da carreira docente na EI se constitui no exercício de saberes em condições complexas de trabalho e emprego, a pesquisa constatou, entre outros aspectos, que o prosseguimento dos processos formativos das professoras também se desenvolve em condições complexas de formação continuada. É a partir dessa problematização que focalizamos, neste artigo, os processos formativos vivenciados pelas iniciantes, no que se refere aos aprendizados da docência na EI. Desse modo, o objetivo é apresentar e problematizar, a partir dos diálogos com as professoras, os processos sucessivos de formação - nas diferentes perspectivas em que se desenvolvem.

Para abordagem dessa problemática sobre os processos formativos no início da carreira docente na EI, organizamos este artigo em duas seções. $\mathrm{Na}$ primeira, contextualizamos os pressupostos teórico-metodológicos que ancoram nossas reflexões, sintetizando o conceito de saberes docentes (TARDIF, 2012) em associação ao princípio dialógico de sentido estabelecido por Bakhtin (2003). Esses conceitos se integram ao princípio de interação dialógica e exotopia (BAKHTIN, 2003). Na segunda seção, abordamos os processos formativos das professoras iniciantes, apresentamos os dizeres das professoras sobre o aprendizado da docência em articulação com a formação inicial e as vivências de formação 
continuada. Para finalizar, tecemos algumas considerações no intuito de manter os diálogos em movimento, com vistas a instar novas propositivas aos processos formativos de professoras iniciantes na EI.

\section{Perspectivas teórico-metodológicas na abordagem do início da carreira}

Estudos sobre formação de professores e trabalho docente (NÓVOA, 2007; 2009; TARDIF, 2012) afirmam que os docentes concluem o período de formação inicial com uma gama de saberes. Esses saberes não se referem somente ao que se aprende durante os anos da graduação, pois reúnem saberes integrados às disciplinas da graduação (considerando estudos, discussões, determinados conteúdos, execução dos estágios curriculares etc.) em interação com saberes pré-existentes (constituídos na sua formação pessoal - no crescimento como ser humano, nas interações familiares, com outros sujeitos), agregando ainda um espaço para novas (re)apropriações, marcando a formação com vivências que se efetivam ao longo da vida. Tardif (2012) indica que os docentes, detentores de saberes de diferentes naturezas, aprendem novos saberes por meio de suas práticas, na associação dos saberes pré-existentes ao contexto de trabalho. Estes novos saberes não se separam dos saberes antigos, mas são reunidos na complexidade do indivíduo, envolvendo tudo que ele é e está se tornando.

Na definição de Tardif (2012), saber docente não se refere apenas à noção de conhecimento dos conteúdos a serem ensinados e métodos a serem utilizados para o ensino, pois reúne, em um sentido bastante abrangente, "uma grande diversidade de objetos, de questões, de problemas relacionados com o trabalho (TARDIF, 2012). O autor afirma que é importante compreender que saber docente está intimamente comprometido com o exercício profissional nas instituições e, especificamente, nas relações de ensino com os educandos. O trabalho docente é um "trabalho multidimensional" que congrega noções concernentes às dimensões pessoais e profissionais do professor, assim como "à sua situação sócio profissional, ao seu trabalho diário na escola e na sala de aula" (TARDIF, 2012, p.17). Essa concepção relaciona organicamente o saber ao professor (sua pessoa) ao seu trabalho, considerando aquilo que ele é e faz e aquilo que ele foi e fez, pois é importante levar em conta a os processos formativos que conduzem à incorporação de novos saberes durante o desenvolvimento do trabalho.

É nesse sentido que Tardif (2012) indica que o início da carreira docente é especialmente significativo para vida dos professores, pois nessa ocasião se efetiva uma intensa mobilização de saberes, originados de diversas fontes. Assim, as condições de início da carreira são cruciais, visto que a consolidação dos saberes docentes é mais difícil quando as condições de trabalho e emprego são precárias. O saber docente se caracteriza como temporal, evolutivo e dinâmico que, de acordo com Tardif (2012, p. 111) "se transforma e se constrói no âmbito de uma carreira, de uma história de vida profissional e implica uma socialização e uma aprendizagem da profissão". Essas reflexões sobre o saber dos professores nos direcionam na busca pela compreensão dos contextos complexos de mobilização de saberes pré-existentes e novos saberes, adquiridos nos processos formativos (re)iniciados e continuados nesse momento da carreira, nos contextos de especificidades do trabalho docente na EI.

A partir da perspectiva de que a docência acontece na associação dos saberes constituídos ao longo da vida, integrando a formação inicial, os novos saberes e novos sentidos gerados com o exercício da docência, no bojo da constituição da vida dos professores, afirmamos a composição de contexto dialógico nos processos formativos, gerando continuamente os sentidos da docência. Para Bakhtin (2003), nossos sentidos se atualizam em contato com outros sentidos (o sentido do outro).

Ele deve sempre entrar em contato com outro sentido para revelar os novos momentos de sua infinidade (assim como a palavra revela suas significações somente num contexto). $O$ sentido não se atualiza sozinho, procede de dois sentidos que se encontram e entram em contato. Não há um "sentido em si". O sentido existe só para outro sentido, com o qual existe conjuntamente. $O$ sentido não existe sozinho (solitário). Por isso não pode haver um sentido primeiro ou último, pois o sentido se situa sempre entre os sentidos, elo na cadeia do sentido que é a única suscetível, em seu todo, de ser uma realidade. Na vida histórica, essa cadeia cresce infinitamente; é por essa razão que cada um dos seus elos se renova sempre; a bem dizer, renasce 
outra vez (BAKHTIN, 2003, p. 386).

Indagar sobre os processos formativos de professoras iniciantes na EI representa a tentativa de tocar os sentidos mobilizados para docência nessa etapa educacional, afirmando o encontro - e o confronto - entre distintos saberes, contextos e sujeitos, podendo gerar sempre novos sentidos. Bakhtin (2003, p. 413; 414) afirma que "não há limites para o contexto dialógico", pois mesmo os sentidos estabelecidos anteriormente não estão estáticos e paralisados, renovando-se "no desenrolar do diálogo subsequente", gerando um renascimento de sentidos. Se associarmos a ideia de sentido bakhtiniano aos saberes docentes, podemos atentar para a relação dialógica dos saberes-sentidos passados, com os saberes-sentidos presentes que, por sua vez, atualizam a memória de futuro do que apontamos para a docência na EI. Para Bakhtin (2003, p. 253, grifo do autor) "o passado determina o presente de um modo criador, e juntamente com o presente, dá dimensão ao futuro que ele predetermina. Atinge-se assim uma plenitude temporal que é sensível, visível". Essa perspectiva de memória de futuro se revela vital para a produção dos novos sentidos a partir dos saberes vivenciados no cotidiano das instituições educacionais.

$\mathrm{Na}$ atenção às relações dialógicas que circunscrevem a docência, os procedimentos da pesquisa, que fornece os dados para estas reflexões, investiram em um movimento de produção/construção dos dados junto às seis professoras iniciantes. A abordagem metodológica foi fundamentada no diálogo entre pesquisadora e professoras, apoiado no conceito bakhtiniano de exotopia. Partimos deste princípio, que estabelece o exercício do excedente de visão, aplicado na relação entre eu e o outro, permitindo a análise do outro, mantendo sua autenticidade.

$O$ excedente da minha visão contém em germe a forma acabada do outro, cujo desabrochar requer que eu lhe complete o horizonte sem the tirar a originalidade. Devo identificar-me com o outro e ver o mundo através de seu sistema de valores, tal como ele o vê; devo colocar-me em seu lugar, e depois, de volta ao meu lugar, completar seu horizonte com tudo o que se descobre do lugar que ocupo, fora dele; devo emoldurá-lo, criar-lhe um ambiente que o acabe, mediante o excedente de minha visão, de meu saber, de meu desejo e de meu sentimento (BAKHTIN, 2003, p.45).

Bakhtin (2003) afirma que, quando estamos diante do outro e ouvimos algo que este fala relativo a uma vivência qualquer, precisamos reconhecer a autenticidade desta enunciação e, de alguma maneira, nos colocarmos no lugar do outro, na tentativa de imaginar como seria aquela vivência. $\mathrm{O}$ autor afirma que "meu ato estético consiste em vivenciá-lo e proporcionar-lhe o acabamento [...] devo assumir o horizonte concreto desse outro, tal como ele o vive" (BAKHTIN, 2003, p. 45). Este esforço gera um produto que reúne as composições de mim mesmo - minha cultura, meus conhecimentos - e a análise que faço da vivência do outro. É nessa reflexão que nos aproximamos das participantes da pesquisa, com o objetivo de produzir excedentes de visão sobre como elas enxergam os processos formativos vivenciados no início da carreira docente na EI. Esse movimento compreende que o produto dessa relação é dialógico, já que o que os sujeitos comunicam nos afetam, nos alteram, nos fazem refletir e assim se constituem como aprendizados, construção de sentidos e, também, de novos questionamentos.

A referência para a escolha dos procedimentos habita na compreensão bakhtiniana de que a ideia que o sujeito tem de si se institui no encontro com o olhar e a palavra do outro. Assim, as minhas ideias e sentidos não são soberanos, estão implicados com diferentes fontes e se compõem com várias possibilidades de endereçamentos, na complexa dialogia da vida. Tudo que instituímos para nós, o fazemos na relação com o outro. Dessa maneira, a abordagem às professoras e o modo de nos colocarmos em diálogo pretendem trazer significações sobre as vivências em curso, considerando também nossa implicação na pesquisa.

Com base nesses princípios, optamos por eleger professores iniciantes com proximidade à pesquisadora, buscando acessar pares de formação inicial, ou seja, colegas do tempo de graduação no curso de pedagogia de uma universidade pública na região sudeste do Brasil que concluíram a graduação junto com a pesquisadora no ano de 2011 e, portanto, estavam no segundo ano de carreira na EI (no período da produção de dados). Com a resposta positiva à busca por seis professores, indicamos que a aposta em vivências e histórias constituídas em proximidade favoreceu a constituição de um clima de liberdade e confiança na produção de reflexões sobre o início da carreira 
docente na EI. As entrevistas individuais foram realizadas nas instituições em que as professoras estavam atuando naquele momento, e as entrevistas coletivas - para as quais dividimos dois grupos de três participantes - foram realizadas na Universidade. Como princípios éticos de proteção aos sujeitos, optamos por utilizar nomes fictícios, escolhidos pelas próprias professoras. Nesses termos, na dialogia com as enunciações das professoras passamos a explorar os dados sobre os processos formativos no início da carreira na EI.

\section{Processos formativos das professoras iniciantes na EI}

No intuído de situar os contextos de trabalho das professoras no primeiro e segundo ano de atuação profissional, apresentamos o seguinte quadro:

Quadro 3 - Atuação das professoras no primeiro e segundo ano de carreira

\begin{tabular}{|c|c|c|}
\hline \multirow{2}{*}{ Professoras } & Primeiro ano de atuação & Segundo ano de atuação \\
\hline & \multicolumn{2}{|c|}{ Condição docente e vínculo de trabalho } \\
\hline Amanda & Prof. ${ }^{a}$ regente em instituição privada de EI & 3 meses: Prof. ${ }^{\text {a }}$ regente em instituição privada \\
\hline Helena & $\begin{array}{c}\text { Prof. }{ }^{a} \text { regente em pública de EI - cargo } \\
\text { estatutário }\end{array}$ & $\begin{array}{l}\text { Prof. a regente em pública de EI - cargo } \\
\text { estatutário }\end{array}$ \\
\hline Júlia & Prof. ${ }^{a}$ regente em instituição privada de EI & $\begin{array}{c}\text { Prof. }^{\text {a }} \text { regente em pública de EI - cargo } \\
\text { estatutário }\end{array}$ \\
\hline Jurema & Prof. ${ }^{a}$ substituta em instituição privada de EI & $\begin{array}{c}\text { Prof. }^{\text {a }} \text { regente em pública de EI - cargo } \\
\text { estatutário }\end{array}$ \\
\hline Karen & Prof. $^{\text {a }}$ substituta em instituição privada de EI & Prof. ${ }^{a}$ regente em instituição privada de EI \\
\hline Sara & Prof. ${ }^{\text {a }}$ regente em instituição privada de EI & Prof. a regente em instituição privada de EI \\
\hline
\end{tabular}

Fonte: Elaborado pela autora

No que se refere à constituição do início da trajetória profissional, as análises dos dados acenam para a observação de que depois da conclusão da formação inicial as professoras encontraram possibilidades de inserção mais imediata em instituições de EI e pertencentes a redes privadas de ensino. Com isso, emerge uma vinculação do início da carreira com as oportunidades de emprego produzindo os sentidos relativos aos desejos ou aproximações com a atuação nessa etapa. Assim, em algumas situações, atuar na EI não se configura como escolha, mas como única alternativa. Os dados indicam que isso aconteceu tanto com professoras que já pretendiam essa etapa quanto com aquelas que tinham outras perspectivas para o início da carreira. Também se remetem à análise dos contextos de trabalho, indicando que, à medida que surgem oportunidades, ocorre uma transferência das redes privadas para as redes públicas de ensino.

De todo modo, cabe assinalar que o desenvolvimento dos processos formativos vivenciados tem relação direta com suas condições de emprego e trabalho. Como podemos observar no quadro, as professoras vivenciam entre o primeiro e segundo ano de trajetória profissional a transição entre redes de ensino. Elas indicam que essas transições marcaram os principais momentos de dificuldades e desafios, pois residiam nessas situações a necessidade de novos aprendizados. Aventamos que iniciar o trabalho em novos contextos implica novos inícios, se não da carreira numa etapa, mas de aproximação a determinados contextos.

Indagamos como as professoras enfrentaram os desafios, especialmente, na associação com os saberes da formação inicial, no intuito de relacionar os sentidos da formação inicial no enfrentamento dos desafios apresentados pelo cotidiano do trabalho.

De modo geral, emerge uma avaliação muito positiva, com afirmações que destacam que os conhecimentos obtidos na formação inicial foram fundamentais para se aperfeiçoar o trabalho. Ainda que esses conhecimentos sejam legitimados, também emergem sentidos ligados à observação de uma falta de preparo para os desafios da prática, como indica a professora Helena.

A gente entra na Educação Infantil com a visão que a gente pode mudar muitas 
coisas. Então a gente chega com muita esperança e eu ainda tenho essa esperança. Só que em alguns momentos a gente encontra uma realidade que demora um pouco mais a atingir o objetivo que a gente tinha. Então quando nós tivemos as disciplinas durante a faculdade parecia que tudo era muito fácil de resolver, 'vou chegar e vou mudar'. Ai quando você chega aqui, temos que manter o foco $e$ a persistência de continuar porque são muitos desafios que vamos encontrar. Eu acho que assim eu me senti despreparada na prática mesmo. (Professora Helena)

Assinalamos que as professoras, diante da percepção de carências para desenvolverem determinados aspectos da prática docente com as crianças pequenas, perceberam a necessidade de buscar meios para avançar em seus processos formativos.

Nesse investimento na continuidade do processo formativo, os sentidos mobilizados pelas professoras não invalidam as aprendizagens da formação inicial por conta das carências sentidas, mas possibilitam assinalar que, em determinados aspectos, ocorre um distanciamento da universidade em relação à complexidade da dinâmica da atuação dos professores. Essas lacunas realçam a importância da formação continuada.

\section{[...] Eu acho que a formação continuada} entra para dar conta destas situações que a universidade está longe [...] acho que a formação inicial pode ser bem cumprida, como para mim foi bem cumprida [...]. Eu acho que a formação continuada vem para preencher estas lacunas que eu acho que não dá conta e nem vai dar, pois acho que não é função da universidade neste momento [...]. (Professora Júlia).

A concepção de formação de professores que temos defendido concebe esta como um processo que se desenvolve ao longo da vida tanto pela ação do indivíduo, que se forma e transforma no decorrer da trajetória, como por movimentos coletivos, para a promoção da reflexão sobre a prática e melhoria do trabalho docente, "que permitem a todos e a cada um se envolver e se comprometer com o avanço da aprendizagem de seus alunos e com a transformação da escola e do sistema de ensino" (PLACCO, 2010, s/p).
Para o reconhecimento da importância da formação continuada para o desenvolvimento profissional, indagamos os tipos de formações vivenciadas, em articulação com as iniciativas para lidar com os desafios do trabalho. Foi possível apurar várias vivências de formação continuada.

A professora Jurema e a Júlia, que atuam em uma mesma rede municipal de ensino, afirmam que havia a previsão de um encontro semanal, com duração de uma hora, para que as professoras realizassem, junto aos gestores das instituições, estudos e debates nos quais se pautassem as questões do cotidiano. Mesmo se tratando de uma mesma proposta, na instituição da professora Jurema os encontros aconteceram como previsto, diferentemente do contexto da instituição da professora Júlia. Jurema afirma que a iniciativa resultou na resolução de várias questões colocadas pelas professoras. Já na instituição da professora Júlia, ela afirma que houve algumas tentativas, mas sem sucesso. Os momentos eram improdutivos, as docentes não demonstravam desejo de participar e todos pareciam preferir iniciativas mais individuais para resolução dos problemas.

A professora Helena, que atua em outra rede municipal, afirma que também eram previstos encontros semanais para estudos e discussões, mas os encontros acabavam sendo dedicados a informes, definições sobre eventos da instituição e outras atividades, em meio a adversidades decorrentes das condições de trabalho:

É uma hora que os professores ficam doidos para ir embora, pois tem professores que precisam ir para outras escolas, também fica mais para alguma pendência tipo: discutir o que vai ser a mostra cultural, o que vai ser dia das mães, então fica para este momento quando o grupo está todo junto. (Professora Helena)

Essas situações assinalam os desafios ao se desenvolver um projeto coletivo institucional implicado com a formação, considerando os interesses dos sujeitos envolvidos, as condições de trabalho, as ações e as estratégias para o desenvolvimento da formação, a organização da gestão das instituições para negociar as prioridades, entre outras dimensões comprometidas ao desenvolvimento profissional.

O trajeto de estudo das vivências de formação, no que tange ao cotidiano das professoras Sara e Amanda sobre a formação continuada nas 
instituições privadas, refere-se a encontros semanais ou quinzenais, que contavam com a participação de profissionais externos às instituições. No caso da professora Amanda, os temas mudavam a cada semana e envolviam professores de todas as etapas de ensino da instituição. Além disso, havia outras oportunidades de discutir as questões cotidianas com colegas. Amanda afirma que esses encontros contribuíram muito para seu aprendizado da docência no primeiro ano de carreira.

[Acontecia] Toda quarta-feira. E era muito enriquecedor [...] muito mesmo. A maioria das quartas-feiras eram palestras, reuniões, [com] psicólogos, neurologistas [...] não falava do meu problema específico... Porque a quarta-feira é para os professores da Educação Infantil até o Ensino Médio... Então não falava do meu problema, mas ajudava bastante a conhecer o universo da criança [...] falava muito sobre questões médicas [...] vinham sociólogos, muitas pessoas ligadas à educação e ligadas a áreas que influenciam muito a educação iam fazer essas palestras. [...] Às vezes às quartas-feiras eram liberadas pra você sentar com a colega que trabalha junto com você na outra turma... Então era o momento de você sentar "e aí, está onde na sua turma, ah, eu estou assim, estou com dificuldade nisso" então você tinha um tempo também pra poder conversar com a outra pessoa... Então era muito enriquecedor. (Professora Amanda)

Essas vivências permitem assinalar também os desafios para negociar, no bojo de um projeto coletivo de formação, as emergências de cada um e dos aprendizados coletivos, investindo também em parcerias no desenvolvimento do trabalho.

A professora Sara também afirma que aconteciam encontros quinzenais na instituição privada em que atua, com o destaque para uma sistematicidade de composição de cursos com temas específicos. Exemplificando, ela informa sobre um curso que auxiliou as professoras na elaboração dos relatórios que deveriam produzir sobre as atividades realizadas com as crianças. A professora se sentiu auxiliada por acessar meios para corresponder às expectativas da instituição e dos pais:

Me ajudou não na parte de escrita, mas na parte de poder passar para o papel de pegar a pratica e transformar em teoria, porque eu preciso fazer relatório descritivo da criança, como tipo de comportamento, evolução, quando a gente percebe alguma coisa de diferente. A gente tem que ter um registro disso principalmente nessa etapa de quatro e cinco anos [...] então essas formações me ajudaram mais nesse sentido, porque é mais fácil você ler na teoria e fazer na pratica agora você pegar a pratica e fazer na teoria eu senti um pouco de dificuldade. (Professora Sara)

Agregamos, assim, a essas reflexões sobre os processos formativos continuados a observação de que, se estes ganham pertinência nas demandas do trabalho eles também se constituem com endereçamentos, geralmente ligados à melhoria do trabalho educativo, buscando corresponder as expectativas dos interlocutores.

A professora Karen afirma que não houve iniciativas de formação continuada na instituição privada na qual atua e que buscou por si mesma estudar e se aprofundar nas questões que sentia necessidade de compreender melhor. Karen buscou fazer o curso especialização em psicopedagogia.

Assim como Karen, as professoras Jurema, Amanda e Helena também fizeram cursos de especialização. Elas afirmam que, por mais que os assuntos abordados sejam amplos, os cursos ajudaram no desenvolvimento do trabalho, principalmente por apresentarem a associação entre teoria e prática, mais bem compreendida por elas que passaram a atuar no cotidiano das instituições.

Cabe marcar que os processos formativos agregam iniciativas institucionais e mobilizações mais individuais, no bojo das oportunidades contextuais de formação. Esses processos estão implicados com vários estímulos e cálculos de horizontes na constituição da carreira. No caso de cursos de pós-graduação, Karen assinala mais o desejo de continuar estudando do que a busca por respostas aos desafios, de soluções práticas para o cotidiano. Além disso, para Karen, a pós-graduação representa acréscimos de pontos em provas de títulos em futuros concursos públicos. Para Amanda e Helena, a busca pela pós-graduação também é incentivada pela possibilidade de aumento do salário no plano de carreira instituído nos municípios. Além da pós-graduação lato sensu, a professora Helena também iniciou, no segundo ano de carreira, o curso de Mestrado em Educação. Ela indica que a busca pelo mestrado se deu pelo desejo 
de aprofundar as questões de Inclusão de crianças com deficiências na EI e, também, pela necessidade de aquisição de maiores títulos na carreira para o ingresso na docência no Ensino Superior.

A análise desse conjunto de dados sobre formação inicial e continuada, ainda que a formação inicial tenha um papel imprescindível no preparo dos profissionais, possibilitou entender que não se trata de atribuir a ela a responsabilidade por prever e responder ao conjunto de possíveis dificuldades enfrentadas no ingresso na profissão. Compreendemos, também, que o exercício da profissão pode carrear a necessidade e possibilidade de continuação dos professos formativos. A associação dos saberes constituídos na formação inicial contribui intensamente no aprendizado da docência no início da carreira.

No caso das professoras, interlocutoras na pesquisa, mesmo observando problemas em algumas questões da formação inicial, as professoras reconhecem que a concepção de formação como um processo contínuo pode auxiliar nas dúvidas e dificuldades que surgem ao longo da trajetória. Todavia, o desenvolvimento profissional por meio de ações específicas de formação continuada não foi vivenciado pela maioria das professoras, principalmente pela falta de iniciativas sistematizadas, organizadas de acordo com os contextos específicos, que respondam aos interesses e necessidades dos docentes na instituição. Assim, destacamos a importância de constituir oportunidades de formação que continuem os processos mobilizados com a formação inicial. Processos que, reconhecendo as especificidades da primeira etapa da educação básica, reconheçam também as especificidades dos sujeitos que se dirigem a esse campo profissional.

Com os dados assinalamos que não captamos nenhum tipo de acompanhamento às professoras iniciantes, seja nas instituições privadas ou redes e instituições públicas. Elas foram recebidas da mesma maneira que as docentes com mais tempo de carreira e assumiram as mesmas responsabilidades e exigências para o trabalho. Nesse contexto, geralmente desenvolveram processos formativos de aprendizado por meio de iniciativas individuais que, embora envolvam outros docentes - que cooperaram para o enfrentamento das dificuldades -, não integram um conjunto de ações específicas para sua formação contínua que agregassem os desafios próprios das professoras iniciantes.

O tipo de mobilização individual para enfrentamento de dificuldades que contribuiu nos processos formativos e se mostrou recorrente foi a busca de ajuda com outras professoras nas instituições (geralmente com docentes com mais tempo de carreira). As parcerias com as outras professoras ou com gestores as auxiliam efetivamente na condução de situações difíceis e no desenvolvimento de ações que ainda não se sabe como fazer. Assim, o desenvolvimento de parcerias para o enfrentamento das situações cotidianas - em suas dinâmicas distintas -se mostra fonte de aprendizagem da docência na EI.

[...] As coisas que você sente dificuldade não é no livro que você quer recorrer, você quer procurar pessoas que já tenham feito aquilo. Ano passado eu não fiz nada [no sentido de buscar pós-graduação] porque você não sente necessidade, porque a ansiedade não está em querer buscar mais conhecimento teórico. [...] Tinha um grupo muito bom de professores que me ajudou bastante [...] Elas foram uma das coisas que me fizeram dar certo [...] Tanto me dando dicas, detalhezinhos, me falando aquelas coisas que só o professor pode te falar [...]. (Professora Amanda)

Não obstante, algumas iniciantes indicam certa resistência por parte de professores mais experientes em fornecer ajuda. A professora Júlia afirma que buscou fazer parcerias com as professoras que atuam com o grupo de crianças da mesma idade com a qual ela atua (cinco anos), mas sem sucesso. Ela acredita que essa parceria poderia cooperar com o desenvolvimento do trabalho, mas a falta de liberdade não possibilitou a dinâmica de um trabalho em conjunto. Nesse sentido, ela indica que teve que desenvolver e administrar sozinha muitas atividades, contudo, também buscou ajuda com a pedagoga da instituição e com outra professora, que trabalha no grupo três.

A professora Helena afirma que no primeiro ano de atuação recorreu às Auxiliares de EI que atuavam na instituição, pois ela se sentia mais à vontade com elas do que com as professoras. Já no segundo ano de atuação, em uma nova instituição, Helena afirma que contou com a ajuda das pedagogas e outras docentes. Essa situação nos indica que a premissa da importância do estabelecimento de parcerias precisa ser contextualizada nas formas de organização institucional. 
Aqui é bem melhor o ambiente de trabalho, as pedagogas dão muito mais apoio no trabalho pedagógico, elas sentam ao menos de 15 em 15 dias com a gente perguntando como estão as coisas, o que estamos precisando, todo dia vem aqui e dá um bom dia, sempre elogia o trabalho [...] Isto é um estímulo para você fazer mais, pois sei que vou ter o apoio delas. (Professora Helena)

A professora Jurema afirma que a maioria das professoras tinha um bom relacionamento entre elas, por isso, não só com as iniciantes na carreira docente, mas também com aquelas com mais tempo de trajetória profissional. Então, compunham um grupo de discussão, motivado pela busca de solucionar problemas e definir meios de desenvolver o trabalho.

Nossa a gente conversa muito [...] então a gente faz pequenos grupos, tem dificuldades, aí com conversa com uma, conversa com outra, individual, mas é sempre todo mundo sabendo do que está acontecendo, todo mundo dando opinião, todo mundo ajuda, todo mundo da ideia. (Professora Jurema)

Ainda que a recorrência ao auxílio de outras profissionais para a resolução das situações quando o contexto das relações na instituição favorece - seja um destaque, também cabe observar que, na dinâmica do trabalho, muitas coisas precisaram ser resolvidas na hora (sem possibilidade de recorrer a auxílio de terceiros). Assim, as professoras são instadas a reunir conhecimentos, comportamentos, opiniões e crenças:

[...] Tem algumas situações que não tem como você ir para casa pensar, tem coisas que acontecem na hora e você precisa pensar e tomar a decisão naquela hora [...] certas coisas nem podem sair da sala. Isso eu respondo por mim [...] a gente consulta a nós mesmas, não tem para onde correr. (Professora Jurema)

É no processo... [algumas questões] eu tento sanar na hora. $\mathrm{Na}$ verdade a gente tem que separar as nossas crenças do julgamento do que a gente acha que é certo e errado. Às vezes eu vou dar uma resposta a um aluno pelo meu pensamento do que é certo ou errado, mas não é o que eu concordo. (Professora Júlia)

Destacamos a natureza heterogênea do saber docente (TARDIF, 2012), pois, para resolver determinados conflitos e/ou dificuldades, cada professora mobilizou conhecimentos e formas de saber-fazer que foram sendo aprendidos e adquiridos a partir de diversas fontes: em sua própria história de vida e formação como cidadã; no aprendizado de perspectivas teóricas variadas sobre a concepção da infância e das interações na infância; enfim, nas vivências profissionais vividas até ali. Tardif (2012, p. 109) indica que, também por essa configuração de constituição, o saber experiencial não se ancora em um conjunto de conhecimentos padronizado e lógico, mas em "vários conhecimentos e sobre um saber-fazer que são mobilizados e utilizados em função dos contextos variáveis e contingentes da prática profissional".

Assim, os processos formativos vivenciados pelas professoras contêm situações de reinvenção da própria prática diante de uma situação conflituosa. A professora Júlia relata a necessidade que sentiu de mudar sua intenção e prática de ensino para atender às questões percebidas por ela no comportamento das crianças do Grupo 5.

Por exemplo, eu não concordo com a alfabetização na educação infantil. Quando eu cheguei aqui eu tinha outro pensamento [...]Então eu percebi que se eu ficasse só dando atividade para aprender a ler $e$ escrever e ignorasse esses outros traços eu não ia conseguir dar aula [...] (Professora Júlia)

Tardif (2012) afirma que o enfrentamento das dificuldades - seja por meio de parcerias ou por meio de mobilizações autônomas dos saberes acumulados -constantemente leva as professoras iniciantes à reinvenção da própria prática. A docência na EI envolve ações de educação e cuidado que se relacionam com a "ampliação das experiências e conhecimentos das crianças a respeito de si mesmas, do seu grupo social, das possibilidades de explicação da realidade próxima e distante (...)" (SILVA, 2013, p. 34). Portanto, essa dinâmica exige das docentes da EI, além de conhecimentos gerais e específicos, a necessidade de reaprender e refletir sobre a prática ao longo da vida profissional em associação às demandas das 
crianças e suas famílias.

Nesse quadro de composição da docência na EI, destacamos as premissas bakhtinianas sobre o modo como somos alterados pelas interações e o modo como empreendemos esforços para responder aos conflitos. Bakhtin (2003) afirma que um sujeito, ao analisar o outro, empreende inevitavelmente um julgamento da situação deste outro. O sujeito se aproxima do outro com uma visão de mundo já formada a partir de determinados pontos de vista e busca compreender. $\mathrm{O}$ autor fala desse movimento como um ato de compreensão, que, se dialógico, não tem fim em si mesmo, mas sim o poder de fazer os sujeitos modificarem e/ou renunciarem pontos de vista iniciais, compondo novas possibilidades de sentidos. Então, na busca pela compreensão do outro "desenvolve-se uma luta cujo resultado é a mudança mútua e o enriquecimento" (BAKHTIN, 2003 , p. 383). Nessa dialogia, no contexto de enfrentamento das dificuldades, o movimento de compreensão do trabalho na EI, muitas vezes, levou as professoras a abrir mão de pontos de vista já constituídos e a buscar novos modos de se colocar no desenvolvimento de sua profissionalidade. Situações como essas indicam também que a mobilização de processos formativos no contexto do trabalho também ocorre estimulada pelas relações com as crianças. Logo, assinalamos que a constituição da docência na EI, entrelaçada aos processos formativos, carreia vários desafios envolvendo vários interlocutores e iniciativas de ação que afetam o desenvolvimento profissional, em especial, dos professores iniciantes. De todo modo, com a pesquisa evidenciamos que o trabalho na EI mobiliza as professoras a (re)aprenderem e (re)significarem suas práticas; esse processo se faz implicado em oportunidades carreadas no contexto institucional que, por sua vez, também estão implicados com o desenvolvimento das políticas públicas associadas à EI, em especial, com as políticas de formação.

\section{Considerações finais}

Analisar e problematizar os processos formativos de professoras iniciantes na EI nos conduz em um campo de estudo implicado em condições de formação, trabalho e emprego dos trabalhadores que atuam nessa etapa. Nesse sentido, a partir dos diálogos com as professoras sobre os aprendizados da docência nos diferentes contextos de trabalho, observamos que os aprendizados da docência foram mobilizados a partir de iniciativas individuais e também coletivas (em vários movimentos associativos, desde pares a projetos coletivos de formação), impulsionados pelos saberes adquiridos e também gerando novos saberes. Nesse movimento, as professoras foram compondo suas maneiras de fazer, integrando iniciativas pessoais a interlocuções e ajuda de outros docentes, movimentando os saberes acumulados e instando novos saberes necessários aos desafios do cotidiano do trabalho. Nesse contexto, as ações de formação continuada, envolvidas nas condições de cada contexto, foram vivenciadas com uma sistematicidade muito diferenciada. Isso contribuiu nas condições dadas para o desenvolvimento profissional das professoras em início de carreira. De modo generalizado, as docentes foram integradas às ações de formação continuada que abrangem assuntos variados, não focalizando o processo de adaptação na relação das professoras iniciantes com a instituição e delas com as diferentes demandas do cotidiano.

Os saberes docentes também foram sendo constituídos em contextos de improviso e de atitudes independentes, por vezes, isoladas. Embora essa situação represente as dificuldades vivenciadas também por professores com mais tempo de carreira em todas as etapas da Educação Básica, refletimos sobre a necessidade de um acompanhamento (no sentido de apoio), específico às professoras iniciantes, articulado nas instituições por meio de ações cotidianas que contribuam com o desenvolvimento profissional das docentes. Indicamos que as parcerias são mais do que meios possíveis ao aprendizado da docência, são subsídios para processos de formação sucessivos, pautado no reconhecimento dos saberes dos outros sujeitos envolvidos no contexto.

As ações de formação continuada precisam se concretizar a fim de consolidar as aprendizagens das docentes iniciantes, integrando os saberes inerentes às novas demandas de inserção no trabalho no campo da EI, em especial, observando as demandas próprias do trabalho na instituição e com os diferentes grupos de crianças. Por meio da pesquisa observamos a necessidade de integração entre as profissionais que atuam nesta etapa através de situações planejadas para tratar das especificidades das crianças na instituição, valorizando os processos cooperativos entre profissionais. Nessa dinâmica, é possível fortalecer diálogos e estudos que potencializem os modos de agir e a melhoria do atendimento às crianças e, ainda, invistam no fortalecimento da EI. 
No fechamento das abordagens desses aspectos da pesquisa, consideramos, sobretudo, a necessidade de que a formação das professoras de EI ganhe importância no bojo da assertiva da formação como um processo contínuo. Afirmamos a importância de que a formação inicial ganhe novos investimentos e a formação continuada seja associada à iniciação à docência, em conformidade com as conquistas da etapa, que vêm se consolidando como campo de trabalho e desenvolvimento dos indivíduos recebidos por ela. Desse modo, na diversidade dos processos de formação assinalados na pesquisa, ainda que em meio às condições desfavoráveis, prosseguimos acreditando em uma educação voltada especificamente a crianças de zero a seis anos. Sobretudo, acreditamos num contexto em que as professoras vivenciem o desenvolvimento profissional progressivo, que seja esse um campo marcado pela lógica de valorização, cujas iniciativas de ações, em seus variados caminhos, invistam na EI e façam recuar as condições de precarização do trabalho docente, ainda tão presentes.

\section{Referências}

BAKHTIN, M. Estética da criação verbal. São Paulo: Martins Fontes, 2003.

BRASIL. Lei de Diretrizes e bases da Educação Nacional. Lei Federal n. ${ }^{\circ}$ 9.394, 1996. Disponível em <http://www.planalto.gov.br>. Acesso em 13 de fevereiro de 2013.

BRASIL. Política Nacional de Educação Infantil: pelos direitos das crianças de zero a seis anos à educação. Brasília: MEC/SEB/COEDI, 2006. Disponível em < http://www.oei.es/quipu/brasil> Acesso em 13 de fevereiro de 2013.

BRASIL. Resolução $\mathrm{n}^{\circ}$ 5, de 17 de dezembro de 2009. Estabelece Diretrizes Curriculares Nacionais para a Educação Infantil. Brasília: MEC/CNE, 2009. Disponível em < http://portal.mec.gov.br/> Acesso em 13 de fevereiro de 2013.

CAMPOS, M. M. A educação infantil sob o impacto das reformas educacionais. In: SOUZA, J. V. A. et al. (org.). Formação de Professores para educação básica: dez anos da LDB. Belo
Horizonte: Autêntica, 2007.

CASTRO, M. Ciclos profissionais. In: OLIVEIRA, D.A.; DUARTE, A.M.C.; VIEIRA, L.M.F. Dicionário: trabalho, profissão e condição docente. Belo Horizonte: UFMG/Faculdade de Educação, 2010. CDROM

FERREIRA, E. B; CÔCO, V. Gestão na educação infantil e trabalho docente. Revista Retratos da Escola, Brasília, v. 5, n. 9, p. 357-370, jul./dez. 2011. Disponível em <http//www.esforce.org.br> Acesso de 10 de dezembro de 2013.

GERALDI, J. W. Bakhtin tudo ou nada diz aos educadores: os educadores podem dizer muito com Bakhtin. In: FREITAS, M. T. A. (org.) Educação, arte e vida em Bakhtin. Belo Horizonte: Autêntica Editora, 2013.

HUBERMAN, M. O ciclo de vida profissional dos professores. In: NÓVOA, Antônio (org.) Vida de professores. $2^{\mathrm{a}}$ ed. Porto: Porto Editora, 2007, p. 3161.

KNOBLAUCH, A. Aprendendo a ser professora: um estudo sobre a socialização profissional de professoras iniciantes no município de Curitiba. Tese de doutorado. São Paulo: PUCSP, 2008.

LEONE, N. M.; Necessidades formativas dos professores dos anos iniciais na sua inserção no exercício da docência. Dissertação de Mestrado. Presidente Prudente: UEP, 2011.

MARCELO GARCIA, C. Formação de professores: para uma mudança educativa. Porto: Porto, 1999.

MIGLIORAÇA, F. Programa de mentoria da UFSCar e desenvolvimento profissional de três professoras

iniciantes. Tese de doutorado. São Carlos: UFSCar, 2010.

MONTALVÃO, E. C. O desenvolvimento profissional de professoras iniciantes mediante um grupo colaborativo de trabalho. Tese se doutorado. São Carlos: UFSCar, 2008.

NÓVOA, A. Os professores e as histórias da sua vida. In: NÓVOA, A. (Org.). Vidas de professores. 2.ed. Porto: Porto Editora, 2007. p.11-30. 
NÓVOA, A. Professores: imagens do futuro presente. Educa: Lisboa, 2009.

NUNES, M. F., CORSINO, P. E DIDONET, V. Educação Infantil no Brasil: primeira etapa da educação básica. - Brasília: UNESCO, Ministério da Educação/Secretaria de Educação Básica, Fundação Orsa, 2011.

PIENTA, A. C. G. Aprendendo a ser professor: dificuldades e iniciativas na construção das práxis pedagógica do professor iniciante. Dissertação de Mestrado. Curitiba: PUCPR, 2007.

PAPI, S. O. G.; Professoras Iniciantes bemsucedidas: um estudo sobre seu desenvolvimento profissional. Tese de doutorado. Curitiba: PUCPR, 2011.

PINAZZA, M.A. Formação de professores da educação infantil. In: OLIVEIRA, D.A.; DUARTE, A.M.C.; VIEIRA, L.M.F. Dicionário: trabalho, profissão e condição docente. Belo Horizonte: UFMG/Faculdade de Educação, 2010. CDROM.

SILVA, I. O. Professoras da Educação Infantil: formação, identidade e profissionalização. In:
BRASIL/MEC/SED. Docência na Educação Infantil. Salto para o futuro. Ano XXIII - Boletim 10 - Jun, 2013. Disponível em:< http://www.tvbrasil.org.br> Acesso em 10 de dezembro de 2013.

TABOSA, E. W. L.; Práticas de formação continuada no desenvolvimento profissional do (a) professor (a) em Início de Carreira. Dissertação de Mestrado. Recife: UFPE, 2009.

TARDIF, M. Saberes docentes e formação profissional. 13 ${ }^{\mathrm{a}}$ ed. Petrópolis - RJ: Vozes, 2012.

ZUCOLOTTO, V. M. Trabalhadores docentes iniciantes no Espírito Santo: perspectivas da carreira. In: FERREIRA, E. B.; OLIVEIRA, D. A.; VIEIRA, L. F. (Org.). O trabalho docente na educação básica: o Espírito Santo em questão. 1ed.Belo Horizonte: Fino Traço, 2012, p. 199-218.

ZUCOLOTTO, V. M.; CÔCO, V.; Início da carreira docente: possibilidades de inserção na Educação Infantil. In: Trabalhos completos do XII Encontro Estadual da ANPAE-SP e VIII Encontro Regional da ANPAE Sudeste. Campinas: Unicamp/FE, 2012. p. 771-784.

\section{Sobre as autoras:}

Valéria Menassa Zucolotto: Mestre em Educação. Professora-Pesquisadora Bolsista na Universidade Aberta do Brasil/Centro de Referência em Formação e em Educação a Distância/IFES. Docente do Instituto Federal do Espírito Santo (IFES), Serra. Integrante do Grupo de Pesquisa "Formação e Atuação de Educadores".

Valdete Côco: Doutora em Educação. Professora do Programa de Pós-Graduação em Educação, UFES, Vitória. Coordenadora do Grupo de Pesquisa "Formação e Atuação de Educadores". Tutora do Programa de Educação Tutorial Conexões de Saberes: Projeto Educação, UFES.

Artigo recebido em janeiro de 2015.

Artigo aprovado em maio de 2015. 